\title{
ANALISIS KEKERABATAN BEBERAPA TANAMAN MANGGA (Mangifera spp.) BERDASARKAN KARAKTERISTIK MORFOLOGI DAN ANATOMI DAUN
}

\section{KINSHIP ANALYSIS OF MANGO PLANTS (Mangifera spp.) BASED ON MORPHOLOGICAL AND ANATOMICAL CHARACTERISTICS OF FOLIAGE}

\author{
Melandani Luh Putu ${ }^{1}$, Eniek Kriswiyanti, Made Ria Defiani \\ Program Studi Biologi FMIPA Universitas Udayana \\ Email: luhputumelandani@yahoo.co.id
}

\section{INTISARI}

Penelitian bertujuan mengeksplorasi karakteristik morfologi, anatomi dan hubungan kekerabatan antar beberapa jenis mangga (Mangifera sp.). Penelitian dilakukan di Laboratorium Struktur Perkembangan Tumbuhan Jurusan Biologi FMIPA, Universitas Udayana dari bulan April 2015 - Juli 2015. Sepuluh jenis tanaman mangga (Mangifera indica : 'poh arum manis', 'poh bukit', 'poh gedang', 'poh madu', 'poh apel', 'poh golek', 'poh sambuk', 'poh bali', 'poh manalagi') dan Wani (Mangifera caesia.) menunjukan karakter morfologi dan anatomi daun bervariasi serta analisis kekerabatannya menunjukan kesepuluh jenis mangga dikelompokan menjadi 2 kelompok besar berdasarkan tingkat kemiripan. Fenogram menunjukan tingkat kemiripan kesepuluh jenis mangga di Bali dikelompokan (cluster) menjadi dua: kelompok I 'poh arum manis', 'poh bukit', 'poh gedang', 'poh bali', 'poh apel', dan kelompok II yaitu 'poh madu', wani, 'poh golek', 'poh sambuk', 'poh manalagi', dimana dua cluster tersebut memiliki tingkat kemiripan > $63,91 \%$.

Kata Kunci: eksplorasi, fenogram. cluster, Anacardiceae

\section{ABSTRACT}

Study was aimed to explore the characteristics of morphological, anatomical, and phylogenetic relationship between some types of mango (Mangifera sp.). Research conducted in Structures Laboratory of Plant Development Department of Biological Science, University of Udayana from April 2015 - July 2015. Samples were taken from three districts in Bali, that Denpasar, Gianyar and Badung. Ten species of plants of mango (Mangifera indica : 'poh arum manis', 'poh bukit', 'poh gedang', 'poh madu', 'poh apel', 'poh golek', 'poh sambuk', 'poh bali', 'poh manalagi') and Wani (Mangifera caesia.) shows the character of morphology and anatomy of leaves varies as well as the analysis of kinship showed ten types of mangoes grouped into two major groups based on the degree of similarity. Fenogram shows the level of similarity of the ten types of mangoes in Bali grouped (cluster) into two: group I 'poh arum manis', 'poh bukit', 'poh gedang', 'poh bali', 'poh apel', and group II, namely 'poh madu', 'wani', 'poh golek', 'poh sambuk', 'poh manalagi' where two clusters have a degree of similarity $>63.91 \%$.

Keywords: exploration, fenogram, cluster, Anacardiaceae

\section{PENDAHULUAN}

Mangga (Mangifera sp.) merupakan tanaman buah tahunan berupa pohon yang berasal dari Negara India menyebar ke wilayah Asia Tenggara termasuk Malaysia dan Indonesia. Mangga berpotensi di kembangkan karena mempunyai tingkat keragaman genetik yang tinggi sehingga plasmanutfah mangga perlu dilestarikan. Variasi pada bentuk, ukuran dan warna buah mangga menunjukkan keragaman genetik yang tinggi (Nilasari et.al., 2013).

Di Indonesia, keberadaan pohon mangga berlimpah. Buah mangga kaya vitamin, sumber mineral dan banyak mengandung senyawa antioksidan yang mampu mencegah penyakit kanker (Setyadjit dan Sulusi, 2005). Manfaat buah mangga bagi kesehatan tubuh misalnya meningkatkan sistem kekebalan tubuh, menjaga kesehatan mata, membuat kulit lebih cerah, membantu melancarkan pencernaan, mengobati panas dalam.

Mangga termasuk marga Mangifera, yang terdiri dari 35-40 anggota, dan suku Anacardiaceae (Hou,1978). Habitus pohon mangga dapat mencapai tinggi 10-40 $\mathrm{m}$. Batang mangga tegak, bercabang kuat dan berdaun lebat membentuk tajuk oval atau memanjang, dengan diameter sampai $10 \mathrm{~m}$. Kulit batang tebal dan kasar serta bersisik pada bekas tangkai daun. Kulit batang yang tua berwarna coklat keabuan, kelabu tua sampai kehitaman. Kekerabatan pada pohon mangga dapat dilakukan dengan cara mengklasifikasikan bentuk-bentuk morfologi tanaman mangga (Konsterman dan Bompard, 1993).

Mangga merupakan salah satu komoditas unggulan Bali yang sangat potensial dikembangkan untuk peningkatan ekspor. Tanaman mangga banyak dibudidayakan pada daerah beriklim kering, misalnya di Kabupaten Buleleng dan Karangasem. Macam mangga yang dominan di Bali saat ini ialah 'Arumanis', 'Lali Jiwa', 'Manalagi', dan 'Golek'. Penyelamatan kultivar-kultivar lokal dan kerabat dekatnya perlu dilakukan dengan menganalisis kekerabatan jenis mangga tersebut (Swastika, 2014).

Penelitian tentang kekerabatan 9 jenis mangga di Provinsi Riau telah dilakukan berdasarkan ciri morfologi $(80$ karakter) dan fluoresensi klorofil. Hasil kekerabatan satu kladogram dengan 2 klad utama yaitu klad 1 terdiri atas Mangifera torquendra dan klad II terdiri atas Mangifera foetida, Mangifera odorata, Mangifera indica, Mangifera laurina, Mangifera sumatrana, Mangifera seylenica, Mangifera quadrifida dan Mangifera sp. (Swita et al. 2013).

Anto et al. (2013) menganalisis hubungan kekerabatan Macang (Mangifera foetida Lour.) di Sumatera bagian tengah. Mangifera foetida (66 individu) telah diamati karakter morfologi dan agronominya. Hasil analisis menunjukkan 6 karakter saling berkolerasi positif. Nilasari et al. (2013) mengidentifikasi keragaman morfologi daun mangga (Mangifera indica L.) pada tanaman hasil persilangan antara varietas arum manis 143 dengan podang urang umur 2 tahun. Hasil penelitian diperoleh 2 kelompok, kelompok 1 yaitu klon yang memiliki hubungan kekerabatan yang dekat dengan kedua tetuanya (32 klon). Sedangkan kelompok 2 merupakan klon harapan dari hasil persilangan arum manis 143 dan podang urang (12 klon).

Penelitian berdasarkan karakter anatomi daun mangga belum pernah dilakukan di Bali, dimana karakter anatomi dapat menunjang karakter morfologi. Perveen et al. (2007), melakukan penelitian anatomi stomata pada 64 genera tumbuhan dikotil, 28 suku menunjukkan bahwa dari 69 spesies ada 6 tipe stomata yaitu anomositik, parasitic, diasitik, parallelositik, siklositik dan anisositik. Pada tumbuhan dikotil tipe anisositik adalah tipe yang paling dominan ada pada 54 spesies, diikuti tipe parasitic ada 9 spesies dan tipe diasitik (3 spesies), sedangkan parellelositik, siklositik, dan ansositik masing-masing satu spesies. 
Penelitian karakteristik anatomi yang dapat menunjang karakter morfologi juga telah dilakukan oleh Desai dan Raole (2013), yaitu pada 16 taksa subtribus Ischacmineae dari Gujarat India, berdasarkan karakter derivat epidermis dan trikoma, seperti bentuk sel silica, sel tetangga, stoma, papille.

Beberapa permasalahan takson di bawah spesies (katagori takson infraspesies) salah satunya dapat diselesaikan dengan pendekatan Fenetik berdasarkan pada seberapa besar kesamaan atau perbedaan kelompok taksa yang diteliti. Hasil klasifikasi morfologi dan anatomi berupa fenogram. Pendekatan fenetik juga dikenal sebagai taksonomi numeris karena metode analisis karakter menggunakan prosedur numeris. Nilai koefisien yang dihasilkan menunjukkan besarnya kesamaan atau perbedaan dari kelompok taksa yang dipelajari (Rustiami, 2012). Berdasarkan latar belakang di atas, penelitian dilakukan untuk mengkaji hubungan kekerabatan beberapa jenis mangga di Bali berdasarkan karakter morfologi dan anatomi.

\section{MATERI DAN METODE}

Penelitian telah dilaksanakan bulan April sampai Juli 2015. Pengambilan sampel dilakukan di Kabupaten Gianyar, Denpasar dan Badung Provinsi Bali. Kemudian pembuatan preparat dan pengamatan pada morfologi dan anatomi daun di lakukan di Laboratorium Struktur Perkembangan tumbuhan Prodi Biologi, Fakultas MIPA, Universitas Udayana.

Sampel daun dipetik sebanyak 20 helai dari setiap macam pohon mangga ( 'poh gedang', wani, 'golek', 'madu', 'arum manis', 'manalagi', 'apel', 'bukit', 'sambuk', 'bali') di Kabupaten Denpasar, Gianyar, dan Badung Provinsi Bali, kemudian diamati dan diukur pada bentuk daun, panjang, lebar, ujung, pangkal, tangkai, tepi, panjang tangkai daun, lebar tangkai daun, jumlah anak tulang daun, warna permukaan atas, warna permukaan bawah, dimana setiap jenis mangga digunakan 3 individu. Sampel daun yang digunakan adalah daun yang duduk ke 5-6 dari bawah pada 10 cabang/individu. Pengamatan pada sampel penelitian anatomi pada setiap daun diambil 2 irisan penampang melintang, dan 1 irisan penampang bujur bagian tengah daun sebanyak 5 helai daun untuk tiap-tiap individu yang dipilih secara acak. Kemudian diletakan pada gelas benda, ditetesi air dan pewarna $1 \%$ safranin dalam air. Tahap selanjutnya pengamatan mikroskopis dengan bantuan mikroskop olympus perbesaran 100x untuk sayatan penampang melintang, dan perbesaran 400x untuk sayatan penampang bujur, kemudian diukur dan diamati: tebal daun, jumlah lapisan sel, jumlah sel tetangga dan bentu sel penutup, panjang stoma, lebar stoma, index stoma, tipe bentuk stoma, jumlah dan bentuk trikoma jika ada.

Data yang diperoleh dari penelitian merupakan data kualitatif dan data kuantitatif, data tersebut disajikan dalam bentuk tabel OTU (Operational Taxonomy Unit, terlampir) kemudian digunakan analisis Multivariate dengan program Minitab 14 Vis untuk mendapatkan Fenogram yang menggambarkan hubungan kekerabatan antar jenis-jenis mangga.

Berdasarkan hasil analisis kekerabatan antar jenis mangga dengan menggunakan program Minitabs Vis 14 didapatkan gambar fenogram pada gambar (Gambar 1).

Fenogram menunjukan bahwa berdasarkan tingkat kemiripan (> 63.91\%) kesepuluh jenis mangga di Bali dapat dikelompokan (cluster) menjadi dua, yaitu: kelompok I 'mangga arum manis', 'mangga bukit', 'mangga gedang', 'mangga bali', 'mangga apel', dan kelompok II 'mangga madu', wani, 'golek', 'sambuk', 'manalagi'. Pada cluster I 'mangga arum manis', 'mangga bukit', 'mangga gedang', 'mangga bali' mengelompok dengan 'mangga apel' dimana tingkat kemiripannya yaitu sebesar $81,87 \%$, 'mangga arum manis' dan 'mangga bukit' mengelompok dengan 'mangga gedang' dan 'mangga bali' dengan tingkat kemiripan 83,65\%, 'mangga arum manis' dan 'mangga bukit' mempunyai tingkat kekerabatan yang paling dekat, yaitu $91,77 \%$, 'mangga gedang' dan 'mangga bali' mempunyai tingkat kemiripan $84,60 \%$. Pada cluster 2 'mangga madu', wani dan 'mangga golek' mengelompok dengan 'mangga sambuk' dan 'mangga manalagi' dimana mempunyai tingkat kemiripan 71,94 \%, 'mangga madu mengelompok dengan wani dan golek dimana mempunyai tingkat kemiripan $81,87 \%$, wani mengelompok dengan 'mangga golek' dengan tingkat kemiripan 82,73\%. 'Mangga sambuk' mengelompok dengan 'mangga manalagi' dengan tingkat kemiripan 86,88 \%. 'Mangga arum manis' dan mangga manalagi mempunyai tingkat kemiripan yang paling jauh.

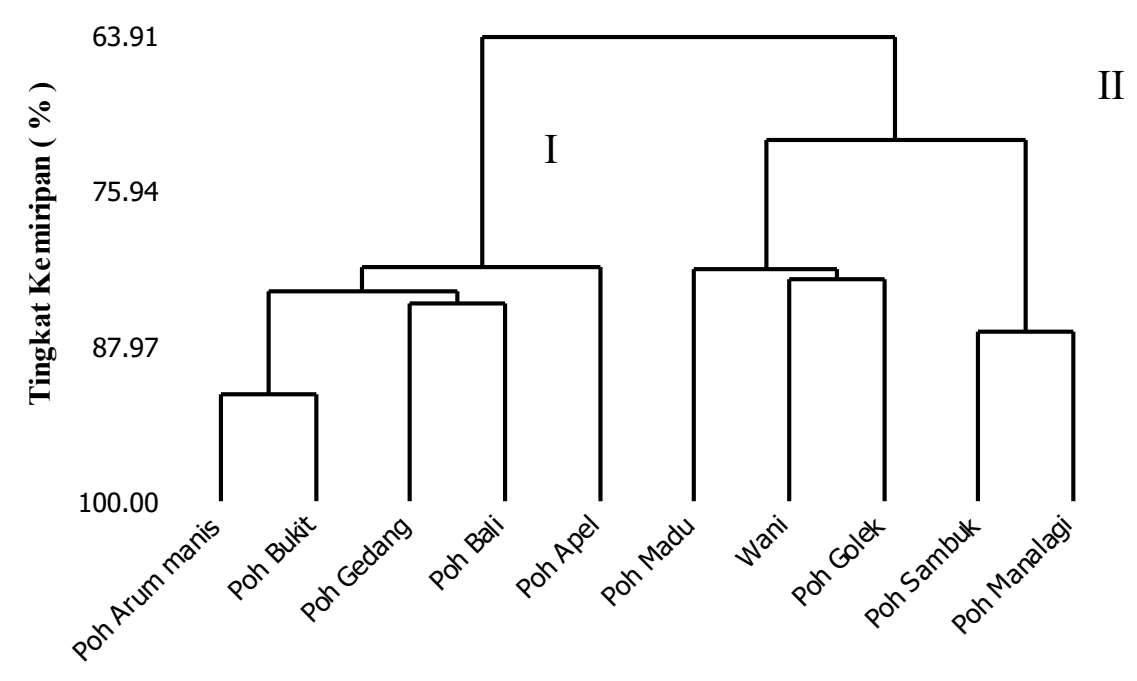

Gambar 1. Hubungan kekerabatan antar sepuluh jenis mangga di Bali

\section{PEMBAHASAN}

Mangifera sp. sebagian besar mempunyai bentuk tajuk agak bulat. Dari sepuluh jenis mangga, sembilan diantaranya mempunyai bentuk tajuk agak bulat, yaitu: 'poh arum manis', 'poh bukit', 'poh gedang', 'poh madu', wani, 'poh apel', 'poh golek', 'poh sambuk' dan 'poh manalagi', dan hanya satu yang mempunyai bentuk tajuk jorong ke atas, yaitu: 'poh bali'. Warna pucuk hijau terang atau kuning kehijauan pada jenis 'poh arum manis', 'poh bukit', 'poh gedang', 'poh madu', wani, 'poh apel', 'poh golek' dan 'poh manalagi', sedangkan 'poh sambuk' dan 'poh bali' mempunyai warna pucuk hijau gelap. Semua letak daun pada cabang semi tegak atau menghadap ke atas, ini sesuai dengan fungsi daun yang berfungsi sebagai transportasi dan menangkap cahaya untuk fotosintesis (Tjitrosoepomo, 2005). Dari sepuluh macam mangga, Sembilan diantaranya yaitu 'poh arum manis', 'poh bukit', 'poh gedang', 'poh madu', wani, 'poh golek', 'poh manalagi', 'poh sambuk' dan 'poh bali' mempunyai warna kulit batang coklat, dan hanya satu yang memiliki warna kulit batang putih kecoklatan yaitu 'poh apel', dan semua dari sepuluh jenis mangga mempunyai tekstur batang yang tebal, kasar dan bersisik.

Mangifera sp. termasuk daun yang tidak lengkap karena hanya memiliki tangkai daun (petioles) dan helaian daun (lamina) saja, dan sebagian besar Mangifera spp mempunyai bentuk daun bangun lanset.Variasi pada bentuk, ukuran dan warna daun mangga menunjukan adanya keragaman genetik yang cukup luas (Nilasari, 2013). Bentuk daun sembilan dari sepuluh jenis mangga diantaranya 'poh 
arum manis', 'poh bukit', 'poh gedang', 'poh madu', 'poh golek', 'poh manalagi', 'poh sambuk', 'poh bali', 'poh apel' mempunyai bentuk daun lanset, dan hanya satu yang mempunyai bentuk daun memanjang, yaitu wani. Menurut Tjitrosoepomo (2005) perbandingan panjang dan lebar daun dapat digunakan untuk menentukan bangun daun. Poh bali mempunyai daun paling panjang yaitu $15,5-35,1 \mathrm{~cm}$, sedangkan 'poh apel' mempunyai panjang daun yang paling pendek 11,3-17,8 cm. 'Poh bali' mempunyai daun yang paling lebar yaitu 4,5 - 9,3 cm dan yang paling sempit yaitu 'poh sambuk' dengan lebar 2,6- 4,8 cm. Dari sepuluh jenis mangga, semuanya mempunyai bentuk ujung dan pangkal daun runcing, dimana ujung daun runcing jika kedua tepi daun di kanan dan kiri ibu tulang sedikit demi sedikit menuju ke atas dan pertemuannya pada puncak daun membentuk suatu sudut lancip, dan pangkal daun runcing biasanya terdapat pada bangun daun memanjang dan lanset, daun mangga mempunyai tekstur daging daun yang tipis tetapi cukup kaku, dengan tepi daun rata, dan permukaan daun licin yang disebabkan oleh lapisan lilin (Tjitrosoepomo, 2005).

Warna permukaan atas dan permukaan bawah pada Mangifera spp mempunyai warna hijau yang bervariasi. Pada poh arum manis, poh gedang, poh madu, wani, poh apel, poh manalagi, poh golek mempunyai warna permukaan atas hijau, sedangkan pada poh bali, poh bukit dan poh sambuk mempunyai warna permukaan atas berwarna hijau tua, pada permukaan bawah daun, dari sepuluh jenis mangga, tiga diantaranya berwarna hijau, yaitu wani, sambuk dan bali, sedang tujuh lainnya berwana hijau muda. Dalam menyebutkan warna daun sangat berpengaruh perseorangan, ini disebabkan karena warna tidak ada ukuran yang obyektif, dan warna daun suatu jenis tumbuhan dapat juga berubah menurut keadaan tempat tumbuhnya dan erat sekali hubungannya dengan persediaan air dan makanan serta penyinaran (cari pengaruh warna) (Tjitrosoepomo, 2005). Aroma daun pada Mangifera sp. juga bervariasi, pada poh arum, poh gedang, wani, poh apel, poh sambuk dan poh manalagi mempunyai aroma daun rendah, dan poh bukit, poh madu, poh golek dan poh bali mempunyai aroma daun yang kuat.

Panjang dan lebar tangkai daun tidak mempengaruhi ukuran panjang dan lebar dari helaian daun Mangifera sp. Pada poh golek mempunyai ukuran paling panjang pada tangkai daun bagian atasnya yaitu 2,1-6,5 cm, dan yang paling pendek tangkai daun bagian atas yaitu pada poh apel 1,2-3,1 cm, pada tangkai atas mangga yang mempunyai ukuran paling lebar yaitu wani $3-5 \mathrm{~mm}$, dan yang paling sempit yaitu pada poh apel 2-3 $\mathrm{mm}$, poh manalagi mempunyai ukuran panjang pangkal tangkai yang paling panjang yaitu $0,7-2,1 \mathrm{~cm}$, dan yang paling pendek yaitu poh apel 0,2 - 0,6 cm, wani mempunyai ukuran pangkal tangkai paling lebar yaitu wani 4$6 \mathrm{~mm}$, dan yang paling sempit yaitu $3-4 \mathrm{~mm}$ pada poh apel.Umumnya tangkai daun berbentuk silinder dengan sisi atas agak pipih dan menebal pada pangkalnya (Tjitrosoepomo, 1993). Susunan anak tulang atau tulang cabang menyirip genap gasal, dengan jumlah paling banyak pada mangga 54- 66 cabang dan poh apel mempunyai jumlah paling sedikit yaitu 32- 40 cabang. Pada pengamatan yang telah dilakukan, cukup sulit untuk membedakan antar jenis mangga menggunakan karakter morfologi, ini disebabkan karena setiap jenis memiliki kemiripan satu dengan lainnya (Swita, et al. 2013).

Dalam pengamatan sayatan transversal daun, pada sembilan jenis mangga memiliki tipe trikoma non glanduler, yaitu pada poh arum manis, poh bukit, poh gedang, poh madu, wani, poh apel, poh sambuk, poh bali, poh manalagi, dan hanya satu yang memiliki tipe glanduler, yaitu poh golek, trikhoma berfungsi untuk melindungi dan memantulkan cahaya matahari. Kesepuluh jenis mangga terdapat banyak kristal $\mathrm{Ca}$ oksalat berbentuk pasir yang berfungsi untuk menahan terjadinya penguapan yang berlebihan (Lakitan,1996), jaringan palisade memiliki lebih dari satu lapis sehingga disebut dengan multilateral. Jaringan spons yang paling banyak terdapat pada mangga arum manis dan mangga golek sebanyak 12 lapisan, dan yang paling sedikit adalah mangga bali yaitu sebanyak 7 lapisan.

\section{SIMPULAN}

Pengamatan dari sepuluh jenis mangga, hanya wani yang mempunyai bentuk daun memanjang (Oblong), dan sembilan jenis mangga lainnya mempunyai bentuk daun lanset, pada karakteristik anatomi daun juga mempunyai kemiripan satu dengan yang lainnya, seperti mempunyai tipe stoma, tipe sel penutup, dan tipe sel tetangga yang sama, tetapi sebagian besar kesamaan dan perbedaan karakteristik dari sepuluh jenis mangga tersebut dapat di tentukan berdasarkan variasi ukurannya. Fenogram menunjukan tingkat kemiripan lebih dari $63,91 \%$ kesepuluh macam mangga dapat dikelompokan (cluster) menjadi dua: dua cluster memiliki tingkat kemiripan $63,91 \%$. 'Poh arum manis' mempunyai tingkat kemiripan paling dekat dengan 'poh bukit' dan paling jauh mempunyai tingkat kemiripan yaitu 'poh manalagi', karena pada fenogram manalagi mempunyai letak yang paling jauh dengan 'poh arum manis'.

\section{KEPUSTAKAAN}

Anto., Fitmawati, N. Sofiyanti. 2013. Analisis Hubungan Kekerabatan Macang (Mangifera foetida. Lour) di Sumatera Bagian Tengah.Fakultas Matematika dan Ilmu Pengetahuan Alam. Kampus Bina Widya. Pekanbaru.

Desai, R.J and Vinay M. Raole. 2013. Foliar Micromorphology of Subtribe Ischaeminae, Tribe Andropogoneae, Family Poaceae. The Maharaja Sayajirao University of Baruda. Gujarat, India.

Fujimori, T. 2001. Ecological and Silvicultural Strategis for Sustainable Forest Management. $1^{\text {st }}$ Edition. Elsevier Science B.V. Amsterdam.

Hidayat, E. B. 1995. Anatomi Tumbuhan Berbiji. ITB. Bandung.

Hidayat, T., Pancoro A., Kusumawaty, D., dan Eiadthon, W. 2011.Molecular Diversification and Phylogeny of Mangifera (Anacardeae) In Indonesia and Thailand Proceeding of the International Conference on advanced Sciene, Engineering and Information.Technology, Putrajaya, Malaysia. : 88-91

Hou , D. 1978. Anacardiaceae (revisions). Flora Malesiana, Series J, 8 (3), P: 395-548.

Juad, W.S., Campbel, C.S., Kellog, E.A., Stevens, P.F., dan Donoghue, M.J. 2002. Plant Systematics ; Phylogenetic Approach, $2^{\text {nd }}$ edition Sinauer Associates, Inc. Publisher, Sunderland, Massachusets USA.

Kostermans, A.J.G.H., dan Bompard, J.N. 1993. The Manggoes : Their Botany, Nomenclature, Horticulture and Utilization. IBPGR Academic Press Harcourte Brace \& Company. London.

Lakitan, B. 1996. Fisiologi Pertumbuhan dan Perkembangan Tanaman. Rajawali Pers. Jakarta.

Mulyani, S. 2006. Anatomi Tumbuhan. Kanisius.Yogyakarta. 
Nilasari, A, N. JB.Suwasono., Tatik. 2013. Identifikasi Keragaman Morfologi Daun Mangga (Mangifera indica L.) pada Tanaman Hasil Persilangan antara Varietas Arum manis 143 dengan Podang Urang umur 2 tahun. Jurusan Budidaya Pertanian Fakultas Pertanian. Universitas Brawijaya. Jurnal Produksi

Paramita, O. 2012. Kajian Proses Pembuatan Tepung Buah Mangga (Mangifera indica L) Varietas Arum manis dengan Suhu Perendaman yang berbeda. Jurusan Teknik, Universitas Negeri Semarang (ISSN 23030623).

Perveen, A., R. Abid dan R Fatima. 2007. Stomal Types of Some Dicots Within Flora of Karachi, Pakistan. Pak. J. Bot. 39(4): 1017-1023.

Rai, I. N., Wijana, G. dan Semarajaya. C. G. A. 2008. Idenifikasi Variabilitas genetik Wani Bali (Mangifera caesia Jack.) dengan analisis penanda RAPD. Jurnal Hortikultura 18 (2) 125-134.

Rustiami, H. 2012. Pendekatan Fenetik pada Sistem Klasifikasi. Pusat Penelitian Biologi. LIPI.

Setyadjit, W. dan Sulusi P, 2005.Agroindustri Puree Mangga: Mengatasi Panen Berlimpah. Warta Penelitian dan Pengembangan Pertanian 27(5): 4-5.

Steenis, G. J. J. C. Van. 1978. Flora untuk Sekolah Indonesia di Indonesia. Batavia: Noodhoff-Kolff.
Sumardi, I. 1993. Struktur dan Perkembangan Tumbuhan.Gadjah Mada University Press. Yogyakarta Suskendriyati, H., A.Wijayanti, N. Hidayat dan D. Cahyuning. 2002. Studi Morfologi dan Hubungan Kekerabatan Varietas Salak Pondoh ( Salacca zalacca ( Gaert Voss.) di Dataran tinggi Sleman. Biodiversitas1 (2) 59-64.

Swastika, I. W. 2014.Organisme Pengganggu Tumbuhan (OPT) Utama pada Tanaman Mangga (Mangifera indica) Pada Pengendaliannya. Dinas Pertanian Tanman Pangan Dan Hortikultura. Denpasar.

Swita, A. Fimawati dan Minarni. 2013. Analisis Hubungan Kekerabatan Beberapa Jenis Mangga (Mangifera) Berdasarkan Karakter Morfologi dan Flouresensi Klorofil.Fakultas Matematika dan Ilmu Penetahuan Alam. Kampus Binawidya. Jurnal Produksi Tanaman.

Tenda, E., Tukilo M., Miftahurrachman/. 2009. Hubungan Kekerabatan Genetik Antar Sembilan Alsesi Kelapa asal Sulawesi Utara. Jurnal Litri 15 (13):139-144.

Tjitrosoepomo, G. 1993. Taksonomi Umum, Dasar-dasar Taksonomi Tumbuhan. Gadjah Mada University Press. Yogyakarta

Tjitrosoepomo, G. 2005. Morfologi Tumbuhan. Gadjah Mada University Press. Yogyakarta.

Zaki, I., A. Johan, dan N. Suci. 2015. Penngaruh Pemberian Jus Mangga Terhadap Profil Lipid dan Malondialdohyde pada Tikus yang diberi Minyak Jelantah. Jurnal Gizi Indonesia. 